\title{
Discurso e prática religiosa nas Comunidades Eclesiais de Base italianas e brasileiras: um estudo comparativo com base na teoria da mudança social de Max Weber ${ }^{1}$
}

\author{
Speech and religious practice in the Basic Ecclesial Communities in Italy and \\ Brazil: a comparative study on the theory of social change by Max Weber)
}

Marinete Luzia Francisca de Souza*

\begin{abstract}
Resumo
Este estudo é uma reflexão sobre o discurso e a prática nas comunidades Eclesiais de Base no Brasil e na Itália. Buscamos demonstrar, a partir de uma pesquisa empírica e teórica, as relações entres duas Comunidades Eclesiais de Base, a Comunidade San Paolo (Roma-IT) e a Prelazia de São Félix (Mato Gross-BR), demonstrando que estas baseiam-se em dois elementos: resultam das discussões advindas do Concílio Vaticano II e estão fortemente ligadas a seus líderes. E, ainda, que tais comunidades ligam-se por fortes laços simbólicos. Este fato permitiunos concluir que a Teologia da Libertação empenhou-se em promover mudanças sociais e em criar um corpo simbólico que a corroborasse. Tais análises foram sustentadas pela teoria da transformação social de Max Weber e, ainda, pelos estudos de Karl Mannheim e de Glock e Stark.
\end{abstract}

Palavras-chaves:Transformação social, Teologia da Libertação, prática, discurso.

\begin{abstract}
This study is a reflection of the discourse and practice on the Basic Ecclesial communities in Brazil and Italy. We try to show, from an empirical and theoretical research, the relations between two Christian Base Communities: the San Paolo Community (Rome - IT) and the Prelature of São Félix (BR - Mato Grosso), based on two factors: the result of discussions arising out of Vatican II, and the strong link to its leaders. Such communities bind by strong symbolic ties that really allowed us to conclude that Liberation Theology endeavored to promote social changes and to create a symbolic body that corroborates it. Such analysis was supported by the theory of social transformation of Max Weber, by the studies of Karl Mannheim and Glock and Stark.
\end{abstract}

Keywords: Social Transformation; Liberation Theology, Practice, Discourse.

Comunicação submetida em 04 de abril de 2011 e aprovada em 03 de dezembro de 2011.

${ }^{1} \mathrm{O}$ projeto de investigação Un'analisi della teologia della liberazione attraverso la teoria del cambiamento sociale: tra teoria e prassi de que resulta este artigo foi realizado com o apoio do Programa Alban, Programa de Becas de Alto Nível para a América Latina (bolsa n. E06M103356BR) e resultou numa dissertação de mestrado defendida no Master Internazionale di Secondo livello in Scienza della Cultura e della Religione/Università Degli Studio Roma Tre (Roma- IT) em fevereiro de 2010.

* Doutoranda em Literatura Portuguesa (investigação e ensino) pela Faculdade de Letras da Universidade de Coimbra, bolsista CAPES (Programa de Doutorado Pleno no Exterior). País de origem: Brasil. E-mail: marineteluzia@hotmail.com.

Horizonte, Belo Horizonte, v. 9, n. 24, p. 1131-1147, dez. 2011 - ISSN: 2175-5841 


\section{Introdução}

A prática e o dicurso religioso são elementos em constante remodelação face à história e às mudanças no interior das próprias religiões. No caso específico do catolicismo, ocorreu, nas décadas de sessenta e setenta do século XX, uma significativa aproximação, com outras formas de entender o ser humano, isto é, com a Psicologia, a Sociologia, e mesmo com a comunicação social, provocando uma interessante forma de interlocução com o mundo moderno e favorecendo o interesse de diversos setores da sociedade em relação ao fenômeno religioso.

O papel social da religião foi, então, praticamente remodelado, de acordo com as exigências de um mundo em franco desenvolvimento econômico. A religião procurou recolocar-se socialmente e um grupo de leigos e religiosos sustentaram a ideia de que isso só ocorreria se esta pudesse dar alguma resposta concreta aos seus fiéis e se a sacralização da vida resultasse em melhorias concretas para o dia-a-dia destes. Assim, a luta pela justiça social adquiriu, do ponto de vista do discurso, um tom religioso. Do ponto de vista prático, um tom engajado e social. Esta ação privilegiada se deu, principalmente, por meio das Comunidades Eclesiais de Base - CEBs.

Tal fato provocou um intenso debate dentro e fora da Igreja Católica, o que será matéria do presente texto, focando, em especial, as ações dele resultantes. Foi sendo gestado o seu sonho histórico de interagir e conviver; tal processo deu-se pela relação de um grupo de católicos progressistas com pensadores marxistas e existencialistas; com movimentos juvenis e operários; com o contato com comunidades autóctones e, mais tarde, com movimentos feministas e de gênero.

Estudamos, ao longo de dois anos, a Comunidade de Base San Paolo (Roma-IT) e a Prelazia de São Félix do Araguaia, buscando identificar que contribuições externas recebeu a Teologia ou Igreja da Libertação e de que modo as contribuições oriundas de outras áreas são conjugadas com a opção cristã dessas comunidades.Tal processo de pesquisa envolveu observação participante, entrevistas e análise críticas.

Temos, então, uma forma de entender a fé que pressupõe abertura a outros elementos da vida e que pressupõe mudanças práticas na vida do fiel e da sociedade. Há maior preocupação com a qualidade do discutido que com a quantidade de participantes; os grupos ligados à Teologia da Libertação condenam aquelas formas de reportar-se à religião 
que não respeitem a diversidade religiosa e as especificidades de cada local. Percebe-se, como acentuou Amaral (2006, p.31), que não é a força "demográfica" da Igreja da Libertação que impressiona, mas a força moral e espiritual, sua capacidade de propor debates. Apresenta ela, claramente, um propósito: juntar "fé e vida", "fé e sociedade", "profecia e história".

No Brasil, embora o laicato pluralista não contasse com o apoio da maior parte da hierarquia católica, conseguiu demonstrar sua importância e introduzir novos conceitos de fé. Mesmo quando o laicato tornou-se menos inibido, a Igreja da Libertação encontrou lugar no clero e na Conferência Nacional dos Bispos do Brasil - CNBB. Na Itália, o número de bispos que apoiaram as comunidades de base é mais reduzido que no Brasil. Veja-se, por exemplo, o que Novelli afirma a esse respeito do tema:

\footnotetext{
Com o tempo, as diferenças cresceram por causa da forte repressão e marginalização operada pela Vaticano e pelos bispos. Por exemplo, Dom Giovani Franzoni foi supenso de sua função sacerdotal e passou ao estado laical. Em 1974, após o referendo sobre o divórcio, a repressão da hierarquia atingiu mais de 300 sacerdotes e religiosos, que se tinha manifestado contrariamente às orientações do Vaticano ${ }^{2}$.(SOUZA, 2010, p.226)
}

Todavia, nos dois casos, as principais relações sociais dos católicos estão inseridas no conjunto das mundanças sociais que ocorreram após as duas guerras mundiais, o que obriga a olhar a questão do laicato de esquerda comparativamente a movimentos voltados para as teorias sociais e não somente para as religiosas.

Há, porém, diferenças significativas. Destaco a formação escolar dos leigos e a história da Igreja Católica em cada um dos países. No caso da Itália, trata-se de uma comunidade de pessoas com formação superior — jornalistas, professores, assistentes sociais, ex-padres, médicos etc. A comunidade brasileira é formada, principalmente, por camponeses (sobretudo à época de sua fundação).

Veja-se que o momento histórico vivido em cada um dos países interferiu nas questões levantadas pelas comunidades de base, mas segundo o que pude observar e ler, lançou-se mão (em ambos os casos) da mensagem bíblica libertária, profética e evangélica

\footnotetext{
${ }^{2}$ Nel tempo le differenze sono cresciute per la forte repressione ed emarginazione operata dal Vaticano e dai Vescovi. Per esempio don Giovanni Franzoni è stato sospeso a divinis e poi ridotto allo stato laicale. Nel 1974 a seguito del referendum sul divorzio la repressione della gerarchia colpì più di trecento sacerdoti e religiosi che si erano impegnati diversmente da come voleva il Vaticano. (SOUZA, 2010, p.226)
} 
para tratar de assuntos sociais e políticos. Amaral (2006, p. 43) identifica uma luta pela conquista dos bens simbólicos baseada na noção de "campo simbólico" cunhada por Bourdieu.

Ambas as comunidades investigadas estão inseridas no processo iniciado na segunda metade do século XX, quando o Catolicismo é confrontado com duas outras modalidades, ambas resultado do aggiornamento promovido pelo Concílio Vaticano II: o catolicismo New Age ou pentecostal no qual se fazem celebrações de massa, baseadas na cura da alma e o catolicismo da libertação alheio às massas, mas preocupado com a coletividade. Ou seja, a primeira está para uma relação entre Deus e o fiel; a segunda — de que entendemos fazerem parte as comunidades San Paolo e Prelazia de São Félix do Araguaia — propõe que a relação com Deus deve ser mediada pela relação com o outro.

Tanto no que refere à comunidade brasileira como no que refere à italiana foi possível verificar que o conjunto de ideias (dimensão ideológica ou crença religiosa) que as sustenta está ligado à dimensão experiencial (experiência religiosa), intelectual (conceitos com os quais a religião é pensada), ritualística (práticas religiosas) e dimensão consequente (efeitos na vida diária), havendo uma possibilidade de aplicação de todas estas categorias sistematizadas pelos americanos Glock e Strak (apud AMATUZZI, 1998).

As entrevistas que fizemos foram importantes para situarmo-nos no corpo ideológico das comunidades de base italiana e brasileira e para esclarecer dúvidas a respeito da história da Teologia da Libertação, mas também, por outro lado, nos deram um retrato bastante fiável de como houve envolvimento dos entrevistados e um comprometimento de suas vidas com a causa na qual acreditavam. Por fim, a forma como se desenvolve a ação na comunidade de base San Paolo e o uso de símbolos como o anel de tucum e a memória de mártires do continente americano, em São Félix do Araguaia levam-me a afirmar que há um corpo simbólico ideológico que sustenta e liga as diferentes comunidades. Para Casanova (apud AMARAL 2006, p. 55), existe, para cada forma de entender a religião, uma espécie de bens simbólicos que atuariam no convencimento de adeptos.

O presente artigo compreende uma parte de um trabalho realizado para a obtenção do título de mestre na Univesità Degli Studio Roma Tre. Para realização da discussão proposta, organizamos o texto da seguinte forma: em primeiro lugar, apresentamos uma leitura interpretativa da Teologia da libertação à luz da sociologia da religião; em segundo 
lugar, discutiremos o lugar que a prática religiosa ocupa nas Comunidades Eclesiais de Base, relacionando-a com o papel que os líderes Giovanni Franzoni e Pedro Casaldáliga ocupam da Teologia da Libertação.

\section{Uma leitura interpretativa da Teologia da libertação à luz da sociologia da religião}

A grande difusão da Teologia da Libertação na América Latina provocou também uma intensa reflexão sobre o tema. Metz (apud AMARAL 2006, p. 190) encontra a possibilidade de perguntar onde estava o poder renovador da Igreja na Europa e se o cristianismo ainda poderia responder às necessidades da sociedade burguesa, como teorizara Weber. Ou seja, se o mundo religioso teria contribuído para que fosse criado um mundo não religioso impedindo que se formasse, como anteriormente, uma imagem religiosa da sociedade.

Deve-se ter em conta que, para Weber (apud AMARAL, 2006, p. 136), o diapasão das mudanças sociais, em âmbito religioso, seria dado pelas discussões intelectuais no interior desse grupo religioso que, conduz, por exemplo, a resultados não materiais, caso da ética do trabalho burguês. Nesse caso, cumpre-nos verificar em que medida as discussões sobre métodos e ideias da Teologia da Libertação (TL) iniciados pelo laicato católico no Brasil e na Itália sobrevivem às mudanças no interior da Igreja e passam à sociedade.

Para Amaral (2006, p. 190), essa mudança iniciada pela TL nos quadros laicais, no seio da institucionalização católica, pode ser explicada pela noção de "campo religioso", expressão cunhada por Pierre Bourdieu com base em Max Weber. Segundo Amaral "no campo religioso, estão os agentes religiosos que determinam a dinâmica da elaboração e da inculturação dos conteúdos e de consciência que orientam a ação religiosa".

Bourdieu (apud AMARAL, 2006, p. 190) distingue quatro categorias em Weber. Primeiro, a religião não depende somente das condições de sua produção, mas da sistematização que lhe é dada; segundo, é possível estabelecer uma análise das instituições sociais e políticas a partir das questões simbólico-religiosas que as sustentam; terceiro, o trabalho religioso tem a função de dar autonomia à esfera religiosa e, por isso, estabelece 
alianças com alguns grupos; quarto, essas alianças fazem com que a religião atinja uma esfera extra-religiosa, sua justificação numa determinada sociedade.

Weber concentra-se nos tipos de dominação e é nesse ponto que Bourdieu o seguirá: a dominação é constituída sob arranjos político-econômicos. Tratam-se de estágios culturais pensados a partir da história comparada das religiões.

Sabemos, entretanto, que a dominação é uma forma pela qual se mantém as posições sociais e políticas (não valorativas), de modo que podemos perguntar-nos, então, se haveria uma continuidade dos métodos da Teologia da Libertação em movimentos que lutam contra a dominação como o Movimento dos Sem Terra (MST). Ainda que a religião não se apresente sob a forma igreja (ou instituição), é possível identificar traços religiosos em movimentos que, à primeira vista, não estão ligados à ideia de religiosidade, o que Cipriani (1988) denominou "religiosità diffusa", e Nesti (1985) "religione implicita". A religião ampara-se, portanto, na cultura, demonstrando ter um carácter amplo e histórico.

Pode-se concluir também que a TL adotou métodos de análise social provenientes de outros campos, sendo este o principal fator a fazer coincidir os interesses deste grupo religioso com o de alguns movimentos sociais.

Como vemos, a questão religiosa pressupõe um conjunto de ideias e de símbolos que a sustentem até que encontre outro que se lhe oponha ou apoie de modo eficiente, e continua a manifestar-se sob outras roupagens. Os interesses sociais respeitantes a cada grupo podem estar ligados às questões econômicas; cada tipo de grupo terá um tipo de hábito, mas pode ocorrer também o encontro de interesses resultantes de convicções e estudos realizados. É o caso das organizações que atuam nas questões ambientais e das comunidades ligadas à TL.

Segundo a teoria de Weber, o mundo é um universo de interseções entre esferas de valores, sendo os conflitos entre os diversos campos insuprimíveis, como haviam proposto Marx e Hegel. Cada campo é autônomo, levando sempre a uma possibilidade conflitiva. Assim, para entendermos o modo como a Igreja da Libertação se estruturou, devemos analisar a relação entre sacerdócio e profecia, entre sacerdócio e laicato e a posição que ocupa no campo social, pois houve um profundo debate entre o tradicional e o novo.

Em relação ao conceito de dominação, Cohn (1979, p. 121) dirá: 
[...] trata-se de um conceito fundamental em Weber,[...] porque permite associar duas premissas de seus esquemas analíticos: a da existência na vida social de uma multiplicidade de valores equivalentes, entre os quais não se podem estabelecer critérios estritamente racionais, objetivos e, muito menos, universais de escolha, e da escassez como pano de fundo de toda ação. Da associação entre ambas deriva a ideia de uma associação diferencial de bens valorizados materiais e simbólicos, que se tornam objetos de uma disputa, latente e aberta, acerca de sua condição social $[\ldots]$.

A dominação diz repeito aos interesses que um determinado grupo ou classe põe sob o objeto religioso e sustenta-se, muitas vezes, em símbolos religiosos.Bourdieu (1992, p. 47) afirma que a questão diz respeito ao interesse que um grupo ou classe encontra em um determinado tipo de prática ou crença religiosa e, sobretudo, na produção, reprodução, difusão, e consumo de um determinado tipo de bens de salvação (dentre os quais a própria prática religiosa).

Amaral (2006, p.192) considera que as formas de manifestação simbólica podem dar-se de dois modos: a escassez não material, mas imaterial; a arbitrariedade dos valores que se pode impor por meio do poder simbólico efetivo e, por fim, "as formas de legitimidade".

Trata-se de aliar as formas simbólicas às questões propriamente políticas,cabendo aos seus agentes (leigos, sacerdotes etc) relacionar a estrutura à ordem simbólica a qual se liga. Devemos ter em conta que nos processos de "mudança social", o novo e o velho entram em debate; velhas e novas estruturas convivem "em um processo de adaptação dialético do qual não se conhece o tempo de atuação, mas se intui que será breve $^{3}$ (CANTA, 1974, p.45). Sendo assim, muitas das lutas deram-se no campo simbólico ou extraplolaram o campo meramente religioso.

Existem muitos métodos de planejamento social na perspectiva democrática. Entre eles encontra-se o planejamento para a liberdade (CANTA, 2006) da qual identificamos traços na Teologia da Libertação: para que se trabalhe o planejamento da sociedade não é preciso apenas a mudança das estruturas sociais, mas a construção de homens que possam sustentar tais estruturas.

Assim, a tese da extrarreligiosidade de uma religião deve ser considerada em dois sentidos (ambas concorrem com a anúncio inicial de uma religião ou reforçam-no): pode

3 [...] in processo di adattamento dialettico di cui non si ne conosce il tempo di atuazione ma si intuisce che sarà breve" (CANTA, 1974, p. 45). 
ocorrer sob a forma da manutenção do poder das elites (essa é a visão Bourdieu); ou pode tratar-se de questões práticas que, ligadas a questões místicas e religiosas concorrem para a mudança social, representando e reordenando as questões práticas e teóricas de uma dada religião. Isso ocorre, sobretudo, quando a religião em questão ocupa ou ocupou lugar importante na cena política ou social de uma sociedade, caso da Itália e do Brasil em relação ao Catolicismo. Essa é a tese de Weber (2006), que demonstra que a direção dos estágios religiosos em relação ao mundo é tanto mais oposta quanto mais intectualizada for a religião.

O campo religioso é um campo autônomo que tende, em certos casos, a unir-se a alguns grupos sociais e a distanciar-se de outros campos, buscando relacionar a ordem de vida à ordem religiosas, caso da TL. Ou seja, a TL é uma estrutura bem elaborada teórico e ideologicamente, que pretende opor-se à organização social vigente engendrada por uma rede complexa de leituras e interpretações bíblicas e messiânicas racionalmente sistematizadas "em nível discursivo" (CRUZ, 2006, p. 99). Sustenta-se num complexo messiânico e em ideias libertárias do mundo: o pecado social passa a ser entendido pela Igreja da Libertação como adversário. É possível perceber como os grupos ligados à TL foram superando a crença no que dizia respeito à Igreja e desenvolvendo, cada um a seu modo, um interessante grau de sistematização em relação à forma de interpretar a realidade social, a partir da "leitura popular da Bíblia". Veja-se, porém, que Weber incide nas relações e não nas ações sociais.

Veja-se que a TL funda-se em textos bíblicos do Antigo Testamento como, por exemplo, na libertação da escravidão do povo hebreu do Egito e empresta ao sacerdócio que a ela adere, um discurso de ruptura, enquanto este lhe empresta seu aparato organizacional. Essa forma de ser Igreja chega à Europa onde a mudança já havia sido ensaiada em nível teórico/teológico (logo após a Segunda Guerra na França), mas a experiência das bases só foi possível porque alguns sacertodes e leigos a assumiram, fosse espelhando-se no exemplo prático da América Latina, fosse olhando a realidade social e eclesial na qual estavam inseridos.

Na Itália, as Comunidades Cristãs de Base (CDB) também se organizaram após o Concílio Vaticano II. Contudo, mesmo havendo apoio de alguns bispos e sacerdotes, a hierarquia não se colocou a serviço das comunidades como no Brasil. Porém, de acordo 
com as observações aqui realizadas, conclui-se que, embora isso possa parecer negativo resultou em fato positivo, pois fortaleceu os leigos, o que lhes deu grande resistência e capacidade de organização.

Na opinião de Amaral (2006, p. 199), se, no Brasil, a CNNB não tivesse apoiado as Comunidades Eclesiais de Base, essas não teriam oportunidade de florescer como floresceram: "se não fosse uma hierocracia bem desenvolvida - aqui quero dizer: uma estrutura de dominação - a Igreja brasileira não poderia cumprir o papel de principal oposição no período do militarismo"

Contudo, o Vaticano II não significou somente progressivismo e ação social. Durante os anos em que D. Aluísio Lorscheider foi secretário geral da CNBB, a ênfase foi posta na valorização do catecismo e da doutrina católica. Há, assim, por parte dos líderes da Igreja da Libertação uma tática relacionada à mudança de mentalidade do clero e dos bispos de modo que se pudesse sustentar a mudança, haveria "uma mística da mudança, que certamente geraria novas tácticas. Um número crescente de padres e leigos verificaram esta mudanças" e, depois de um tempo, considera Casanova (1974), ela pode vir a significar algo ${ }^{4}$.

Veja-se, então, que a práxis relaciona-se, no caso da Teologia da Libertação, ao envolvimento em assuntos temporais, havendo um deslocamento da vida contemplativa para a vida ativa. Acredito, então, que as Comunidades de Base são um lugar onde a crítica do conhecimento teológico desenvolvida por correntes progressistas da Igreja Católica, a partir de 1950, ganha contornos práticos e respondem ao que os teólogos produzem, dandolhes subsídios para elaborar suas teorias. Assim como em Weber (1982), a crítica do conhecimento é mais valorizada que a do objeto.

A igreja da libertação é um "sistema" ou um "espaço" estruturado de posições com suas regras próprias. Nele ocorrem lutas entre os agentes e com outros campos sociais. Essa oposição pode tomar a forma de luta entre "antigos" e "modernos", entre "ortodoxos" e "heterodoxos".

\footnotetext{
4 " [...] in the ideology or mystique of change which will surely generate new tactics. An increasing number of priests and religious people are talking about change and after a while it may come to mean something”.(CASANOVA, 1974, p.135).
} 
A religião é assim compreendida tanto do ponto de vista do que representa para o indivíduo como do ponto de vista do que representa para a sociedade e é nesse ponto que as comunidades de base estudadas ligam-se a grupos que propagam valores que lhe são próprios.Nas duas comunidades estudadas, o que encontramos foi a "participação com militância" (PACE, 2007, p. 66): os fieis compartilham os compromissos assumidos e, na maioria das vezes, modelam o tipo de vida que levam aos ideais nos quais acreditam.

\section{As ações nas comunidades de base San Paolo e São Féliz do Araguaia e seus significados}

A forma como tem se dado a prática nas comunidades de base será melhor precisada pela exposição e análise das atividades da Comunidade de Base São Paolo e São Félix do Araguaia. Essa discussão sustentar-se-á através dos dados recolhidos nas visitas realizadas a cada uma das comunidades, a partir das atas das assembleias das comunidades de base e das entrevistas realizadas.

Por intermédio da observação participante que desenvolvi na Comunidade de Base San Paolo, durante o segundo semestre do ano de 2007, de duas visitas a São Félix do Aragauia em 2006 e das leituras de textos informativos, de poesias e de cartas pastorais, pude notar o modo como essa forma de entender a Igreja Católica tem se organizado desde a sua fundação. Nosso olhar direcionou-se para a forma como a TL se concebe e para as ações práticas desenvolvidas por seus membros. Na opinião de Gianni Novelli, em entrevista em maio de 2009:

\footnotetext{
Hoje, as "ações práticas" são muito poucas, porque as comunidades de base têm a sua própria proposta específica social e política. Cada um escolhe as prioridades sob a qual quer basear as suas escolhas. E estas muitas vezes são diversas. Todos, entretanto, são motivados por suas escolhas baseadas na ideia de libertação na qual se encontram ancorados crentes e não crentes ${ }^{5}$. (SOUZA, 2010, p. 226).
}

\footnotetext{
5 Oggi le "azioni pratiche" sono veramente poche perché le comunità di base non hanno una loro proposta politica e sociale specifica. Ognuno sceglie il fronte sul quale schierarsi in base alle sue scelte. E queste non di raro sono assai diverse. Tutti però sono animati dale scelte di liberazionelle quali si trovanno accanto credenti e non credenti. (SOUZA, 2010, p.226).
} 
O papel das comunidades de base é, então, segundo a visão de Gianni Novelli, formar os seus participantes para que esses possam assumir, espontaneamente, compromissos com alguma causa social. Todavia, a comunidade desenvolve ações conjuntas que levam a algum tipo de ação: cursos de língua italiana oferecidos a refugiados políticos; discussão sobre a situação da Palestina, contribuições em dinheiros para comunidades de países em que as pessoas encontram-se em situação de pobreza.

Embora essas reuniões funcionem como estudo teórico, tem o importante papel de ser um lugar de reflexão fora do espaço dos meios de comunicação de massas já que, em muitos casos, a opinião pública é influenciada pelos grandes veículos de comunicação.

Uma das questões bastante discutidas pela Comunidade de Base San Paolo é a dos "dons" e "carismas", levando os participantes a irem percebendo suas potencialidades e a assumirem compromissos com a comunidade. Participei de duas reuniões (uma espécie de círculo de estudos bíblicos) na Comunidade de Base São Paolo na qual se discutia-se, justamente, a questão dos "dons e carismas".

Discorrendo sobre o tema, um dos membros do grupo questionou sobre como seria o futuro da comunidade, pois considerava baixo o fluxo de pessoas jovens, e muitos só a procuravam porque conheciam Giovanni Franzoni ou Gianni Naveli, que sendo pessoas muito carismáticas teriam esse dom de animar a comunidade. Por outro lado, aquela era uma experiência histórica ligada a um momento da Igreja Católica. Assim, colocou-se, então a pergunta ao grupo: "É possível levar avante uma experiência história sem a experimentação do momento em que esta surgiu, sem os laços históricos que a sustentam?" Acentuou-se, ainda, (referindo-se às experiência das comunidades de Base na Itália) que, trata-se de um testemunho diverso e não de outra Igreja.

Cabe aqui discutir o conflito entre as comunidades de base ligadas àTeologia da Libertação e alguns setores da hirarquia católica, pois este conflito liga-se diretamente ao papel que o leigo ocupa dentro da Igreja Católica, confrontando-se, diretamente, com o papel que os padres e bispos ocupam nessa. Foi importante o papel do líder nessas comunidades, pois sua visibilidade e vida está ligada com a forma como o líder se posiciona diante dos demais participantes, provocando o nascimento de uma comunidade capaz de funcionar independentemente de sua presença; e, relaciona-se, também, com a forma como tais comunidades dialogam com outras vertentes cristãs. 
Ao entrevistar Gianni Novelli (em outubro de 2009), perguntei sobre o que pensava sobre o papel do líder nas Comunidades de Base Italianas (CDB). Conforme entrevista realizada com Novelli (SOUZA, 2010, p. 226), o importante papel do líder pode ser ligado ao fato de estas comunidades apresentarem propostas diferentes em relação à comunidade paroquial tradicional; a figura do líder é tido como determinante, sobretudo porque a história das diversas comunidades de base italianas está ligada à repressão da hierarquia contra algum sacerdote incômodo e à repressão de sua ação pastoral.

Ou seja, a compreensão da forma como as CDBs relacionam-se com seus líderes (na Itália e no Brasil) liga-se ao momento histórico em que essas nasceram. De acordo com Mannheim (apud CANTA 2006, p. 63), trata-se do surgimento de "líderes de grupos sociais que estão em condições de propor ideias inovadoras e mudanças também em contextos sociais problemáticos ${ }^{6}$ ". Estudar, concretamente, este grupo permanece uma questão em aberto (CANTA, 2006). Nesse caso, os líderes funcionaram, com sua experiência e formação (em alguns casos dentro dos quadros hierárquicos católicos), como mediadores entre as duas partes, entre a Igreja centrada em questões mais tradicionais e àquela que quer modernizar-se; mas é, também, alguém decidido a posicionar-se em favor da renovação da Igreja.

Franzoni manifestou-se, em entrevista realizada para esta pesquisa, afirmando que acredita que o papel do líder é diferente nas diversas comunidades de base, sendo que, quando o líder é um sacerdote, sua ausência é mais sentida, mas que, algumas comunidades conseguiram desprender-se do papel do líder "sacerdote" e desenvolver sua autonomia. Assim, quando interrogado a respeito afirmou que, na comunidade San Paolo, certamente é assim, mas que em outras comunidades como na Pinerolo ainda vale o provérbio: ferirá o pastor e as ovelhas dispersar-se-ão. (SOUZA, 2010, p. 223).

No caso da Prelazia de São Féliz do Araguaia, os grupos pastorais são coordenados por leigos, mas Pedro Casaldáliga tornou-se uma grande referência não só para os leigos da comunidade que coordena, como também para outras comunidades, principalmente, para aquelas ligadas à Comissão Pastoral da Terra e ao Conselho Missionário Indigenista.

\footnotetext{
${ }^{6}[. .$.$] leaders "di gruppi sociali che sono in grado di propporre idee inovativi i di cambiamenti anche in$ contesti sociali probelmatiche. (CANTA, 2006)
} 
Através das reuniões que participei na Comunidade San Paolo, pude perceber como a comunidade foi se estruturando em torno da ideia de uma comunidade autônoma em relação aos atos litúrgicos. A esse propósito, Novelli afirma em entrevista concedida em Outubro de 2009 que as primeiras mudanças ocorridas após o Concílio Vaticano II foram aquelas em âmbito religioso, pois "retirar o mistério da língua latina das mãos dos sacerdotes apontou para a necessidade de construir uma igreja de iguais e de participantes. Primeiro, nas celebrações litúrgicas e depois em toda a vida da Igreja. Com estas mudanças, temas como as lutas sociais e a política entraram nas assembleias religiosas ${ }^{7}$.

Tanto Franzoni como Novelli acentuam o fato de a comunidade de Base San Paolo dedicar-se a discutir os mais diversos assuntos como, por exemplo, questões de imigração, questões ecológicas, indígenas, a questão da Palestina, o papel da linguagem no mundo contemporâneo, a crise econômica etc. Essa diversidade de temas e interesses reflete-se na diversidade de seções desenvolvidas pelas comunidades São Paolo e Prelazia de São Félix do Araguaia: grupos de jovens, laboratório "dei bambini”, grupos ligados às questões indígenas, à imigração e aos refugiados políticos na Itália e reuniões com os prefeitos da região, no caso da Prelazia de São Félix do Araguaia, para tratar de temas de interesse coletivo.

Este fato demonstra que a forma de ser cristão defendida pelas Comunidades Eclesiais de Base foi amplamente difundida justamente porque alguns dos seus líderes, leigos ou religiosos tornaram-se figuras enigmáticas, seja por seu carisma, seja pela contestação das posições de seus organismos oficiais em relações aos dogmas religiosos e a acontecimentos sociais. Esta opção é expressa por Casaldáliga em entrevista realizada em 2009 (SOUZA, 2010, p. 216):

Eu insisto sempre, falando das CEBs, que o importante é não uma ou muitas comunidades mais ou menos toleradas dentro de um esquema eclesiástico tradicional, mas a comunitariedade de toda a Igreja, de todos os ministérios, de toda a pastoral. Pedimos não apenas "um novo modo de ser Igreja", mas "o novo modo de toda a Igreja ser"; desde a cúpula de Roma até a menorzinha comunidade do nosso sertão.

\footnotetext{
${ }^{7}$ [...] togliere il mistero della lingua latina nelle mani del clero e dare avvio a una chiesa di uguali $e$ partecipanti. Prima alle celebrazioni liturgiche e poi a tutta la vita della chiesa..(SOUZA, 2010, p. 227).
} 
Notemos que o discurso de Casaldáliga, embora se tratasse de uma entrevista, é o de um líder, animador e defensor de uma comunidade. Sua posição de líder fica patentequando o que sobressai no entrevistado é o uso de expressões "eu insisto sempre", "pedimos não apenas um", "um novo modo de ser Igreja", mas "o novo modo de toda a igreja ser". Pude ainda observar o alcance de sua liderança na Romaria dos Mártires da Caminhada da qual participei em 2006. Muito dos participantes desta romaria, membros das CEBs ou de outras pastorais, deslocaram-se à São Félix do Araguaia com o objetivo de celebrar e de renovar as suas conviccões. Esta renovação passa pela memória dos mártires que aconteceram em defesa dos direitos humanos e pela escuta de seus líderes, ocupando Casaldáliga este papel. Logo, o que se conclui é que a Prelazia de São Félix do Aragauia funciona como uma comunidade ampliada, isto é, as comunidades da Prelazia que, embora sejam CEBs, estão ligadas a uma paróquia e a Prelazia não fugindo a organização da diocese tradicional.

Em Roma, tivemos a oportunidade de verificar como a Comunità San Paolo celebra morte de Dom Oscar Romero, geralmente com reflexões sobre a realidade e caminhada pelas ruas da capital italiana. Logo, podemos destacar como elemento comum a ambas as comunidades, a celebração da memória dos mártires que lutaram em defesa dos direitos humanos. A diferença desse tipo de celebração para outras é o fato de que todo o sofrimento pode ser constatatemente reanalisado a partir de diferentes momentos históricos em que ocorrem as celebrações, abrindo a possibilidade utópica da transformação. A ruptura se dá porque a prática dá coesão interna à comunidade.Decorre daí uma importante função de ligar os membros das diferentes comunidades de base através da figura de líderes que sejam conhecidos e cuja ação possa ser utilizada como exemplo pela comunidade. Esse é o caso de Franzonni e de Casaldálgia.

Recorremos, nesse ponto, a Luckmann (2004, p. 80) quando este afirma que certas fórmulas institucionais devem permanecer na memória para que possam ser legitimadas; como ocorrem, porém, nas instituições problemas ao nível da legitimação (concorrência) e da socialização (dificuldade ao nível da interiorização), recorrendo-se a símbolos, materiais ou imateriais, isto é, o conhecimento liga-se aos hábitos e às questões simbólicas, mas também reais. 
A realidade é entendida como aquilo que conhecemos, pois ela é socialmente construída. Sua variedade empírica relaciona-se com a forma com que está estabelecida. É preciso, portanto, conhecer a forma como o conhecimento relaciona-se com o que é real. Esse fato conduz à relação entre conhecimento e realidade histórica, levando-nos a considerar tanto a importância do pensamento utópico como a realidade na qual a vida sustenta seus alicerces, pois a consciência é capaz de deslocar-se para diferentes esferas da realidade.

\section{Considerações finais}

O que tentamos verificar, em termos empíricos, foi como a ação ligada à Teologia da Libertação consolidou-se e perpetuou-se ao longo do tempo. Foi, justamente, a linguagem utópica (simbólica) e afetiva e sua estetização na forma de poesia, afrescos e vestes que permitiram que corpo de conhecimento produzido por esta pudessem ser objetivamente descrito.

Por outro lado, houve uma importante ação dos líderes destas comunidades, cujas vozes passaram a representá-las. Assim, tratados pastorais e teológicos e as notícias sobre as comunidades de base e suas ações foram se constituindo como uma espécie de corpo teórico, a Teologia da Libertação. São, justamente, estes textos - de Leonardo Boff, Giovani Franzonni, Pedro Casaldáliga etc - e o exemplo de líderes como Oscar Romero, Pedro Casaldáliga e Giovani Franzoni que anima as CEBs. Por outro, a TL desafia a seus membros a viverem a dimensão experencial da fé a partir da realidade, o que leva as comunidades de bases a centrarem-se nos problemas das regiões onde estão localizadas.

Trata-se, então, de incorporar as experiências diárias à fé católica, permitindo sua inserção na tradição cristã para depois, disponibilizá-las através de um complexo simbólico, estético e teológico, isto é: "permite a incorporação num campo mais amplo de tradições por via da formação moral, da poesia inspiradora, da alegoria religiosa e outras mais" (BERGER; LUCKMANN, 2004, p. 79). Essa legitimação simbólica permite que se olhe para o conjunto de símbolos em torno da qual os membros das comunidades de base se unem como signos da mudança social. Nesse ponto, é que a teoria de Werber (apud PACE, 2007, p. 59) tem-nos sido útil porque permitiu-nos olhar para a religião não a partir da 
forma como essa permite a validação da ordem social existente, mas sim a partir da forma como essa "possa contibuíre a svilupare i cambiemente sociale e i confliti."

\section{REFERÊNCIAS}

AMARAL,R. R. O milagre político: catolicismo da libertação. 2006, 321 f. Tese (Doutorado em Sociologia), Departamento de Sociologia,Universidade de Brasília, Brasília.

AMATUZZI, M. M. A Experiência Religiosa: estudando depoimentos. Estudos de Psicologia, Campinas: n. 15, v. 2, p. 3-27, 1998.

BERGER, P.; LUCKMANN, T. A construção social da realidade: um livro sobre sociologia do conhecimento. Lisboa: Dinalivro, 2004.

BORGES, A.A.C. Nas veias do Jornal: a terra. Os Sentido Sobre a Carta Pastoral de Dom Pedro Casaldáliga na Imprensa. 2000. 131 f. Dissertação (Mestrado em Linguística), Instituto de Estudos da Linguagem, Universidade Estadual de Campinas, Campinas.

BOURDIEU, P. A economia das trocas simbólicas. São Paulo: Perspectiva, 1992.

CANTA, C. C. Sfondare la notte. Religiosità, modernità e cultura nel pellegrinaggio notturno alla madonna del Divino Amore. Milão: FrancoAgeli, 2004.

CANTA, C. C. Ricostruire la società. Teoria del mutamento sociale in Karl Mannheim. Milão: Franco Angeli, 2006.

CIPRIANI, Roberto. La religione diffusa.Teoria e prassi. Roma: Borla, 1998.

COMUNITÁ CRISTIANA DI BASE. Memoria e progetto. Condivisione eucaristica e partecipazione politica fuori dei recinti.Torre del Greco: Edizioni Qualevita, 2003.

COMUNITÁ CRISTIANA DI BASE. Comunità: Segni di convivialità nella storia. Percorsi concilirare a 40 anni dal Vatiano II. In: XXX INCONTRO NAZIONALE DELLE CDB. Atti del convegno di Chianciano. Napoli: Comunità de Cassano, 2006.

COHN, G. Crítica e resignação: fundamentos da sociologia de Max Weber. São Paulo: T.A. Queiroz, 1979.

CASANOVA, J. Brazil: from oligarchic church to people's church. Plublic religions in the modern world. Chicago: University of Chicago Press, 1994.

MANNHEIM, K. Ideologia e Utopia. Rio de Janeiro:Zahar, 1972. 
MAZZI, E. Percorsi oltri il muro. La profezi e il muro.Verona: Il segno dei Gabrielli Editori, 1995.

MONDIN, B. La giustificazione critica del fenomeno religioso. In: CIPRIANI, R. MURA G. Fenomeno religioso oggi: tradizione, mutamento, negazione. Città del Vaticano: Urbaniana University Press, 2002. p.717-730.

NESTI, A. GIANNONI,A.; DIANICH,S. La religione implicita. Sociologi i teologi a confronti. Roma: EDB, 1994.

PACE, E. Introduzione alla sociologia della religioni. Roma: Carocci, 2007.

SOUZA, M. A criação literária de Dom Pedro Casaldáliga Plá. Revista Panorâmica Multidisciplinar, Cuiabá, n.6 p. 173 -177, 2005.

SOUZA, M. Un'analisi della teologia della liberazione attraverso la teoria del cambiamento sociale: tra teoria e prassi. 2010, 228 f. Dissertação (Master Internazionale di II Livello in "Scienza delle Culture e delle religioni"). Facoltà di Scienze delle Formazione,Università Degli Studi Roma Tre, Roma.

VALÉRIO, M. E. Entre a Cruz e a Foice: Dom Pedro Casaldáliga e a significação religiosa do Araguaia. 2007. 243f. Dissertação (Mestrado em História). Instituto de Filosofia e Ciências Humanas, Universidade Estadual de Campinas, Campinas.

WERBER, M. L'Etica protestante e lo spirito del capitalismo. Milano: BUR, 2006.

WERBER, M. Sobre a teoria das ciências sociais. Lisboa: Editorial Presença, 1977. 